BMJ Open Sport \& Exercise Medicine

\title{
Breaking the myths of competition: a cross-sectional analysis of injuries among CrossFit trained participants
}

\author{
Yuri Feito (D) , ${ }^{1}$ Evanette Burrows, ${ }^{2}$ Loni Tabb, ${ }^{2}$ Kerri-Anne Ciesielka ${ }^{2}$
}

To cite: Feito $Y$, Burrows $E$, Tabb L, et al. Breaking the myths of competition: a cross-sectional analysis of injuries among CrossFit trained participants. BMJ Open Sport \& Exercise Medicine 2020;6:e000750. doi:10.1136/ bmjsem-2020-000750

- Additional material is published online only. To view please visit the journal online (http://dx.doi.org/10.1136/ bmjsem-2020-000750).

Accepted 19 May 2020
Check for updates

\section{C) Author(s) (or their} employer(s)) 2020. Re-use permitted under CC BY-NC. No commercial re-use. See rights and permissions. Published by BMJ.

${ }^{1}$ Exercise Science and Sport Management, Kennesaw State University, Kennesaw, Georgia, USA

${ }^{2}$ Dornsife School of Public Health, Drexel University, Philadelphia, Pennsylvania, USA

Correspondence to Dr Yuri Feito;

yfeito@kennesaw.edu

\section{ABSTRACT}

Objectives The purpose of this study was to examine the injury rates of individuals engaged in CrossFit training and examine the risk of injury associated with competition.

Study design Cross-sectional analysis.

Methods Descriptive statistics, including injury incidence and rates, were examined for individuals reporting participation in a CrossFit sanctioned competition between 2013 and 2017. To examine the odds of being injured, we considered logistic regression models, where the primary independent measure was participation length—individual measures of interest included age, sex, body mass index, CrossFit affiliation and competition status.

Results 3049 individuals completed the survey $(60 \%$ completion rate). All competitors, regardless of competition level, had similar incidence of injury $\left(\chi^{2}=1.1, p=0.571\right)$. For those who reported competing, our calculated injury rate was $0.21-0.54$ injuries per 1000 training hours, while for those not competing, the injury rate was calculated as $0.39-1.30$ injuries per 1000 training hours. Logistic regression demonstrated short length of participation in CrossFit training as the main factor associated with the odds of being injured (OR=1.82; $95 \% \mathrm{Cl}$ : 1.15 to 2.92). Additionally, training at an official CrossFit affiliate appeared to have a protective effect from injury $(0 R=0.85$; $95 \%$ Cl: 0.65, 1.10).

Conclusion Our findings provide evidence of the low risk of injury related to these events. Moreover, these findings support the notion that musculoskeletal injuries may be the result of poor progression plans, which may be minimised by participating in an official CrossFit affiliate.

\section{INTRODUCTION}

Even though high intensity programmes have existed since the late $1970 \mathrm{~s},{ }^{12}$ these programmes have gained popularity among the general population over the last several years. ${ }^{34}$ As a training modality, high-intensity functional training (HIFT), or more commonly known as CrossFit training, merges the components of high-intensity training and functional movements. Recently, Feito and colleagues ${ }^{5}$ offered a definition of what constitutes a HIFT programme-a training style (or programme) that incorporates a variety of functional movements, performed at high-intensity (relative to an individual's

\section{Summary box}

What are the findings?

- In this large, multi-year sample of individuals participating in CrossFit sanctioned competition events does not carry significant risk of injury.

- Our data show that lack of experience with CrossFit training is a significant predictor of injury.

- Training at an official CrossFit affiliate may reduce the risk of injury.

How might it impact on clinical practice in the future?

- Unlike what has been previously reported in the popular media, these findings support the notion that injuries are not the result of higher training loads, instead they are the result of inappropriate and poor progression plans. This study will impact clinical practice by providing clinicians quantifiable evidence to promote progressive training plans to avoid musculoskeletal injuries. Moreover, it provides clinicians quantifiable data regarding the potentia risk for injuries.

ability) and designed to improve parameters of general physical fitness and performance. This study, along with a recent content analysis of the CrossFit literature provides insight into the historical perspective of the training modality, and posits future research directions. ${ }^{56}$

Although limited research exists, ${ }^{6}$ several investigators have evaluated the benefits of $\mathrm{HIFT}^{78}$ programmes, and have concluded these programmes improve general physical skills, ${ }^{8}$ while promoting a strong sense of community, satisfaction and motivation. ${ }^{7910}$ Despite these positive findings, several reports postulate the potential risk of musculoskeletal injuries associated with HIFT programmes, more specifically CrossFit training. ${ }^{11-13}$ Chachula et al reported significant associations between history of prior joint injury and increased prevalence of injury among CrossFit participants ${ }^{14}$; however, these associations are not exclusive to CrossFit training, as similar correlations have been reported 
with more traditional sports. ${ }^{15-17}$ Moreover, recent reviews do not support the claims of increased risk of injury $^{718-21}$ and in general, denote incidence rates range between 0.27 and 3.5 injuries per 1000 hours of training, which are similar to rates of more traditional exercise programmes. ${ }^{22-25}$ In the largest cross-sectional study to-date, Feito and colleagues ${ }^{25}$ examined the incidence of injury of over 3000 participants between 2003 and 2017 and concluded that HIFT is a safe training modality for most, although they warned that those with less than 1 year of experience, as well as those who engage in less than 3 workouts/week are at a higher risk of musculoskeletal injury.

As a sport, CrossFit engages their worldwide affiliates ${ }^{26}$ through an annual competition-the CrossFit games. The goal of the CrossFit Games is to find the 'fittest on earth' through a series of competitions leading to the final competition-The Games. At the local level, The Open, serves as the preliminary round of the competition and consists of five separate workout challenges over 5 consecutive weeks, in which anyone can participate-in 2018, over 400000 participants enrolled in The Open. ${ }^{27}$ The uniqueness of this round of competition is that all workouts are unknown to the participants prior to their release, and typically include a combination of multi-joint and functional movements, with very little equipment required. At the end of the 5 weeks of competitions, the top athletes (male and female) from each of the established regions advance to the next level of competition, known as Regionals. In this phase of the competition, athletes compete in several unknown physical challenges over a 3-day period. After Regionals, the top athletes from each region advance to The Games and compete over a weekend in several new physical challenges to be declared the 'fittest on earth' (detailed description of each phase of the competition can be found at https://games.crossfit. com/ searching by year). It is worth noting, however, that as of 2018, CrossFit, Inc. has significantly altered the competition season and the process of qualification to The Games has been modified to increase worldwide participation, ${ }^{28}$ whereby the Regional competitions have been eliminated, and additional qualifying opportunities have been created through the incorporation of 'sanctionable' events, which take place in different areas of the world, throughout the year.

Even though several reports have elucidated the risk of injury associated with CrossFit training participation, limited data exist on the incidence of injury among individuals who participate in CrossFit sanctioned competitions. Therefore, the purpose of this study was to examine the injury rates among individuals engaged in CrossFit training and the risk of injury associated with those who engaged in CrossFit, Inc. sanctioned competitions over a 4-year period. The objectives of our study were to (1) examine the injury rates of individuals engaged in CrossFit training and (2) examine the risk of injury associated with competition. Based on the available data, we hypothesise that those who are engaged in competitions will have a higher risk for injury, as a result of a greater total volume of training compared with non-competitors.

\section{MATERIALS AND METHODS}

This study involves a cross-sectional analysis of 3049 individuals reporting participation in CrossFit sanctioned events between 2013 and 2017. A detailed description of the survey tool and survey methodology has been published elsewhere. ${ }^{25}$ Briefly, the study used an electronic survey tool (Google Forms, Mountain View, California, USA) to ask participants about their participation in CrossFit training and their history of injury. Inclusion in the study was limited to those over 18 years old, with more than 3 months of CrossFit training experience and who were able to understand written English or Spanish. Snow ball sampling ${ }^{29}$ was used to circulate the survey through the CrossFit community using social networks outlets, email and word of mouth. This type of approach has been deemed appropriate for this type of research. ${ }^{30}$ Surveys were distributed between midDecember and the end of February of the following year in consecutive years (2013-2017) prior to the beginning of the competition season. We chose this time frame to appropriately capture injuries that occurred within the previous year only. The online application Bitly (Bitly, New York, New York, USA) was used to track the number of 'clicks,' which generated an estimate of our global reach and response rate. Both the survey and the online tracking were completely anonymous and did not store IP addresses from any computer. All participants provided consent prior to the beginning of the survey.

\section{Questionnaire}

The questionnaire was designed using a mixed-method strategy ${ }^{32}$ where some survey questions required a determined response and others were open-ended; this allowed participants to elaborate on their individual responses in order to obtain the most information possible from each respondent.

Survey respondents were asked to complete a number of self-reported measures, which were used as independent variables for analysis. Each participant reported demographic information such as age (years), sex (male/ female), height (metres), weight (kilograms), and body mass index (BMI) was calculated from height and weight following standard equation $\left(\mathrm{kg} / \mathrm{m}^{2}\right) .{ }^{33}$ Lastly, the survey asked if individuals trained at an official CrossFit affiliate, as well as if they competed in a CrossFit sanctioned event (The Open, Regional, or The Games). Although we acknowledge most CrossFit participants compete in local competitions, we felt using only sanctioned events would be most appropriate, as it would provide a more concrete measure of when an injury may have occurred.

The questionnaire inquired about weekly participation in CrossFit training, as well as the number of workouts per week. Additionally, the survey asked participants to provide a brief history of injuries incurred during the previous year while participating in this training 
modality. In order to avoid misinterpretation of what constitutes an injury, the survey used the definition provided by Weisenthal et $a l^{34}$ of 'any muscle, tendon, bone, joint, or ligament injury sustained while doing CrossFit that resulted in your consultation with a physician, or healthcare provider AND caused you to stop or reduce your usual physical activity, your typical participation in CrossFit, or caused you to have surgery.' The survey further asked participants to identify the injured body part, and participants were provided an opportunity to briefly elaborate on their injury. Researchers used these open-ended responses to dichotomise this variable into a single injury, if the participants had only reported one injury (eg, hands), or multiple injuries, if they chose multiple sites or the same site multiple times (eg, hands, legs, back etc). Lastly, participants were asked if they participated in CrossFit training at an official affiliate or a non-affiliated facility.

\section{Statistical analysis}

Considering the study design and the limited number of studies currently reporting injury rates for this training modality, both incidence (ie, the number of new cases) ${ }^{35}$ and injury rates ${ }^{36}$ where calculated. We believe reporting both values are important in order to provide comparisons with previously published data and future studies. Additional details of how these measures are used in this context are provided by Feito $e t a l^{25}$

In order to calculate injury rates, we established a 'workout' as the exposure measure, ${ }^{36}$ as individuals could hypothetically experience an injury each time they engage in this training modality, not necessarily the number of days they engage in training. Thus, our calculations included the total number of injuries reported by each participant during the previous years as the numerator. Similarly, a measure to examine the exposure of injury (a workout hour) was created based on previous studies reporting that participants typically complete 60-minute workouts. ${ }^{34} 37$ Therefore, the exposure of injury was calculated as the product of workout session, the frequency of workouts per week and the weeks per year participants engage in this training modality (ie, 1 hour/session $\times$ frequency of workouts/week $\times$ weeks/ year). Intending to examine the injury risk over a year, we considered 50 weeks would be an appropriate minimum (lower-bound) approximation of training for most individuals and used 52 weeks as our maximum approximation (upper bound). These estimates are believed to provide more accurate approximation of the 'real risk' of this activity, considering that exposure may more likely influence injury risk. Considering these rates are typically very small numbers, we report injury rates per 1000 workout hours.

Descriptive statistics, including means and SDs, were calculated for different age groups. Frequency counts and percentages were computed for all categorical variables. To test the independence of categorical variables, we used the $\chi^{2}$ test. Incidence rate, or the number of new cases, ${ }^{35}$ are presented as proportions $(\%)$ based on the total number of surveys completed and incidence rates are calculated based on the number of injuries reported and lower and upper bound assumptions.

To examine the odds of being injured, we considered three logistic regression models. Model 1 was a null model, which only included an intercept term. Model 2 included age, sex, BMI, CrossFit affiliation and competition status. Model 3 extended Model 2 to also include participation length-our primary independent measure of interest. To assess potential multicollinearity of all independent measures considered in these regression models, we evaluated the variance inflation factor. All factors were less than 10-indicative of little to no evidence of significant multicollinearity. ${ }^{38}$ We also examined fit statistics like the Akaike Information Criterion (AIC) to objectively compare the performance of our three models-where the best has the smallest AIC value. ${ }^{39}$ We reported adjusted ORs and their associated 95\% CIs to describe the odds of being injured for all survey participants.

Participation length was our primary independent measure, so we also conducted sensitivity analyses to consider other forms of how participation length was operationalised. First, we considered participation length categorised as less than 1 year, 1-3 years and more than 3 years. Second, we considered the number of weekly workouts categorised as less than 4 workouts/week, 4-6 workouts/week, 7-9 workouts/week and 10 or more workouts/week. Lastly, we considered the number of days of workouts per week categorised as less than 3 days/ week, 3-5 days/week and more than 5 days/week.

All analyses were conducted using R V.3.3.6 ( R Core Team, 2016) and a significance level of alpha of 0.05 was chosen to denote statistical significance; $p$ values are reported as two-tailed.

\section{Patient and public involvement}

Patients and/or the public were not involved in the design, or conduct, or reporting, or dissemination plans of this research.

\section{RESULTS \\ Participants}

Considering the anonymous nature of our survey, we were unable to calculate an actual response rate. However, our tracking application, which recorded the total number of clicks on our survey, reported a total of 5141 total clicks, with a total of 3049 individuals completing the survey; thus, we calculated a completion rate of approximately $60 \%$. Of those, more than half $(1551,51 \%)$ reported participating in the CrossFit Open, with a smaller proportion reaching Regionals $(183,6 \%)$ and The Games (60, $2 \%$ ), as it was to be expected (figure 1). A mean age of $37.3 \pm 9.6$ years was reported. Significant differences were observed among age groups in regards to their participation in competitions $\left(\chi^{2}=20.9, p=0.004\right)$, with those in the between 30 and 34 age group reporting greater participation in a CrossFit sanctioned event (table 1). 

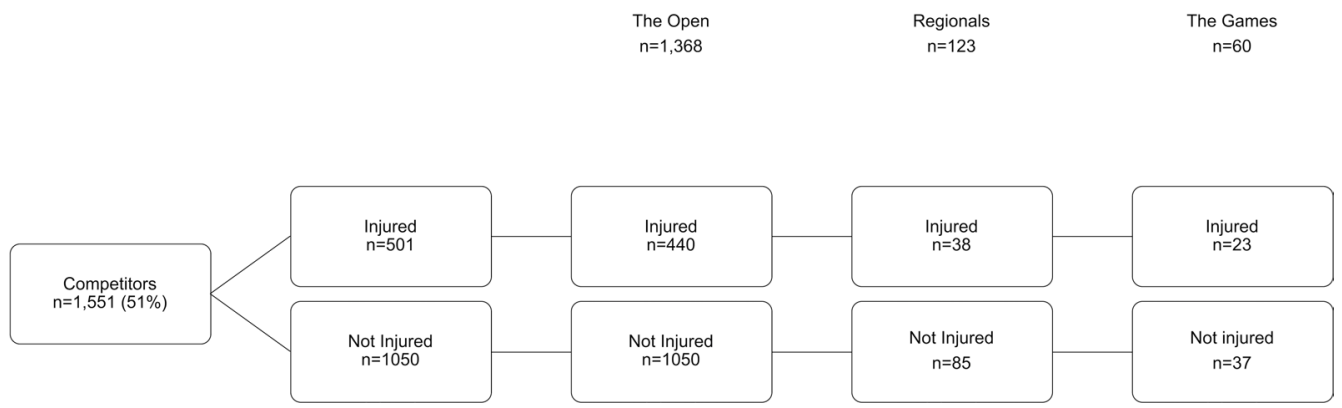

Figure 1 Flowchart of the total number of respondents and surveys completed based on competition and injury status.

Additionally, significant differences were observed between men and women, with men reporting participation in competitions more often than women $\left(\chi^{2}=11.1, p\right.$ $\leq 0.001)$.
Among those who reported competing in a sanctioned event, significant differences were observed for length of participation in CrossFit training, weekly participation, affiliate association and number of workouts per

Table 1 Participant demographics, training, affiliate association and participation frequency in CrossFit training by competition status

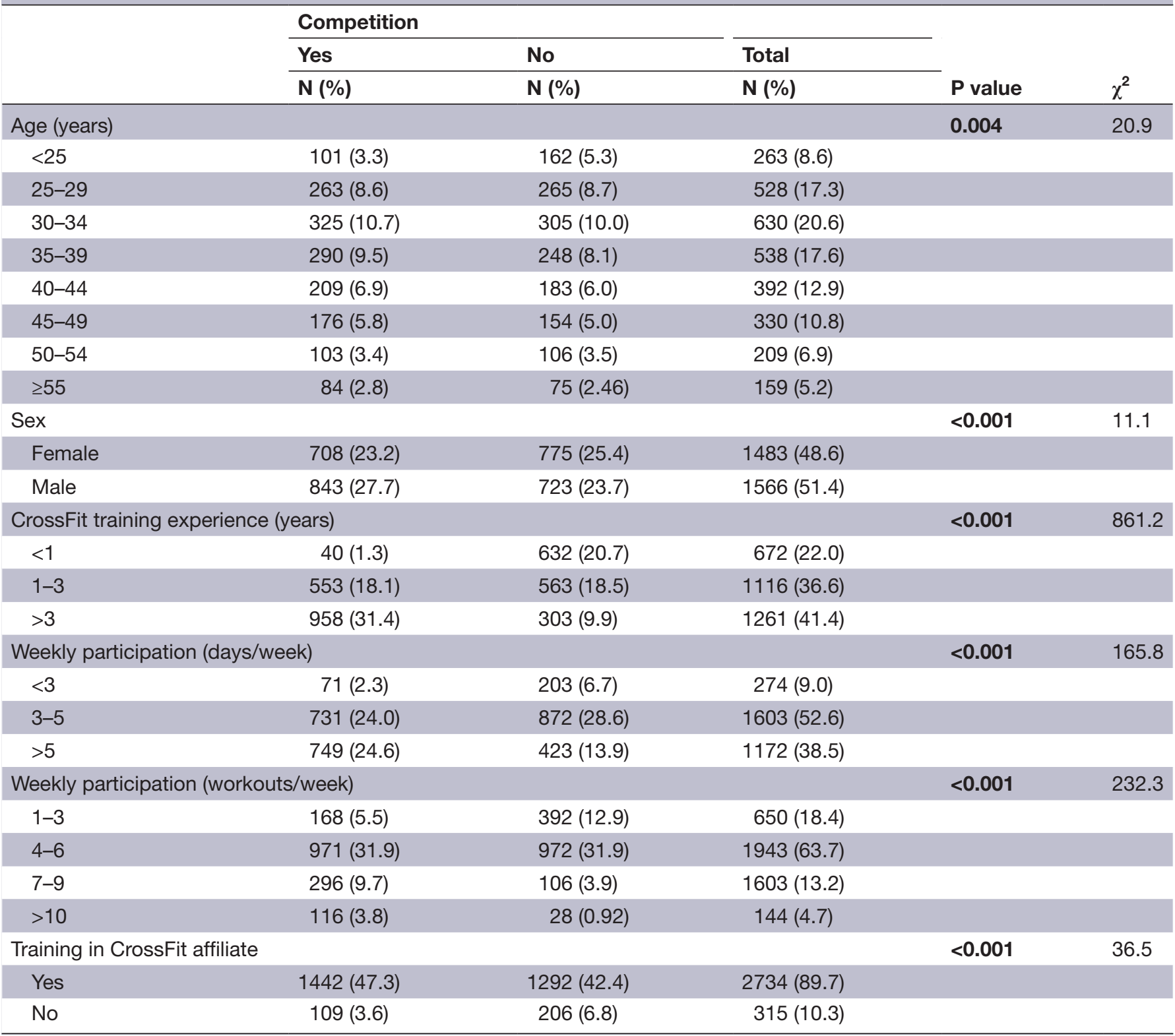


week (table 1). Overall, those who reported competing had more than 3 years of CrossFit training experience (31.4\%), compared with $18.1 \%$ and $1.3 \%$ who reported $1-3$ and less than 1 year of experience, respectively $\left(\chi^{2}=861.2, \mathrm{p} \leq 0.001\right)$. In regards to weekly participation in CrossFit training, those competing, reported training more than 5 days/week $(24.6 \%)$ and between 3 and 5 days/week $(24.0 \%)$, which was significantly different from those participating less than 3 days/week (2.3\%; $\left.\chi^{2}=165.8, p \leq 0.001\right)$. The majority of competitors $(93 \%)$ reported training in a CrossFit affiliate $\left(\chi^{2}=36.5, \mathrm{p}\right.$ $\leq 0.001$; table 1$)$. Among those who did not compete, the vast majority only reported training $3-5$ days/week (28.6\%) (table 1). Interestingly, however, the majority of respondents $(63.7 \%)$ reported completing 4-6 CrossFit workouts/week regardless of competition history, which was considered statistically significant compared with the other groups $\left(\chi^{2}=232.3, \mathrm{p} \leq 0.001\right.$; table 1$)$.

\section{Injury incidence}

A flowchart of the total number of individuals reporting an injury is presented in figure 1. A total of 1551 (51\%) respondents reported participating in a CrossFit sanctioned competition event, with a total of $501(16 \%)$ reporting an injury $\left(\chi^{2}=4.8, p=0.034\right)$. No significant differences were observed $\left(\chi^{2}=0.4, \mathrm{p}=0.511\right)$ between those who competed, or not, and the number of injuries reported. Overall, 318 (34\%) respondents reported a single injury, with 183 (20\%) reporting multiple injuries. We also evaluated the incidence of injury among those who participated at different levels of competition-The Open, Regionals and The Games. Among those who reported an injury, $440(32 \%)$ individuals reported suffering an injury during The Open, while 38 $(31 \%)$ and $23(38 \%)$ of those reaching Regionals and the Games, respectively, had similar incidence of injury $\left(\chi^{2}=1.1, \mathrm{p}=0.571\right)$.

\section{Injury rates}

Injury rates provide an actual measurement for comparison between individuals. ${ }^{36}$ In this sample, injury rates resulted in a severely right tail skewed distribution, with the majority of participants reporting low injury rates. Considering the skewness of the data, we report the overall median with 95\% CIs and mean with SDs. For those who reported competing and based on the assumed number of workout hours per week, our calculated injury rate was 0.21-0.54 injuries per 1000 training hours. Moreover, for those not competing, the injury rate was calculated as $0.39-1.30$ injuries per 1000 training hours.

When evaluating the injury rates for female and male competitors, we see similar injury rates for women (1.130.31 injuries per 1000 training hours), compared with men (1.14-0.33 injuries per 1000 training hours) (online supplementary appendix A). However, these injury rates seem to be inversely related to training frequency as individuals who report competing and engaging in less than

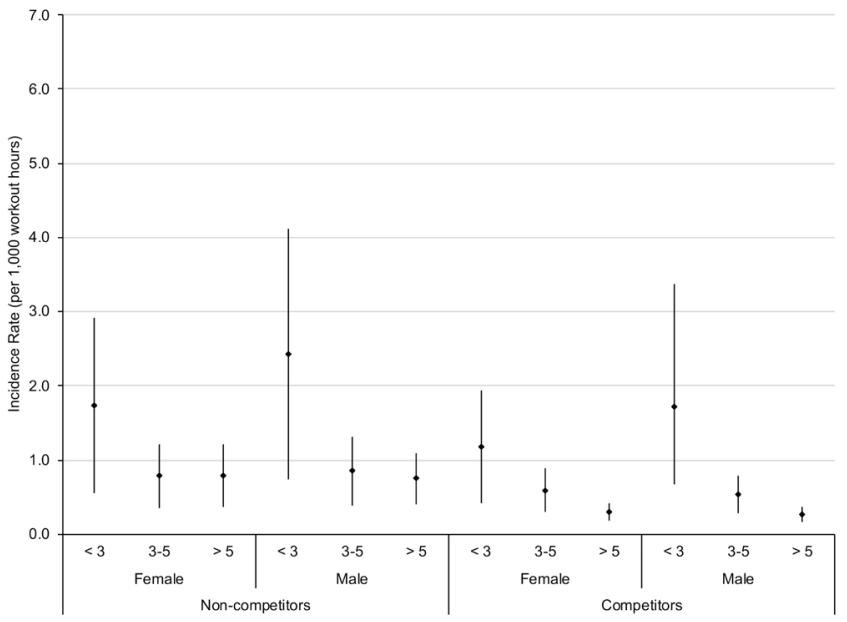

Figure 2 Incidence of injury among competitors by sex and frequency of training (days/week). Incidence rate mean with lower and upper bound assumptions for 50 and 52 weeks assumed for workouts per year, respectively.

3 days/week of training show higher injury rates for both women and men (figure 2).

We were also interested in evaluating how age impacted injury rates among this group of CrossFit competitors (figure 3). Overall, injury rates among competitors did not seem different for individuals training more than 3 days/week; however, for every age-group, those training less than 3 days/week had higher injury rates compared with the other two groups (figure 3A). Among noncompetitors the injury risks tended to be higher than in competitors overall, especially among those training less than 3 days/week (figure 3B).

\section{Regression modelling}

Table 2 presents the logistic regression model results for the odds of being injured in null (Model 1), reduced (Model 2), and fully (Model 3) adjusted settings for this sample $(\mathrm{N}=3049)$ of participants, where the OR, 95\% CIs, and model fit statistics are presented. Of the three models evaluated, Model 3 shows evidence of the best fitting model, with the AIC value being the smallest of all the models considered.

Considering the values included in the model, shorter length of participation in CrossFit training seems to be significantly associated with the odds of being injured. Specifically, for those with the least amount of experience (ie, 3-6 months), their odds of being injured are significantly increased ( $\mathrm{OR}=1.82 ; 95 \%$ CI: 1.15 to 2.92 ) compared with those participants with more than 5 years of participation. For all other participants with more than 6 months of experience, there appears to be a protective effect in terms of participation length; however, these results are not statistically significant. In addition, our regression model suggests that those who compete in CrossFit sanctioned events may have an increased risk of injury ( $\mathrm{OR}=1.07 ; 95 \%$ CI: 0.89 to 1.29$)$, while those training in an official CrossFit affiliate appeared to have a protective effect from being injured $(\mathrm{OR}=0.85 ; 95 \%$ 
CI: 0.65 to 1.10 ) (table 2 ); however, neither of these two factors reached the level of significance established to denote increased or reduced risk $(\mathrm{CI} \neq 1.0){ }^{40}$

We also conducted a sensitivity analysis to the operationalisation of participation, and these results are presented in online supplementary table S1A-C. Online supplementary table S1A considered participation length categorised as less than 1 year, 1-3 years and more than 3 years. Online supplementary table S1B considered the number of weekly workouts categorised as less than 4 workouts/week, 4-6 workouts/week, 7-9 workouts/week and more than 10 workouts/week. Lastly, online supplementary table S1C considered the number of days of workouts per week, categorised as less than 3 days/week, 3-5 days/week and more than 5 days/week. Overall, participants with less than 1 year (compared with over 3 years of participation) of experience and those engaging in CrossFit training less than 3 days/week (compared with over 5 days/week) had an increased risk of injury (25\% and $19 \%$, respectively); however, these results were not statistically significant. In addition, our data suggest that as the number of workouts per week increased (4-6 and 7-9 workouts/week), there was a noticeable protective effect; however, again, these results were not statistically significant.

\section{DISCUSSION}

Considering the staggering growth of CrossFit affiliates over the last decade, ${ }^{41}$ and the continued growth in participation of CrossFit sanctioned events, ${ }^{27} 42$ a critical need exists to evaluate the potential for musculoskeletal injuries associated with these types of competitions. Using a cross-sectional approach, we have attempted to provide insight into this question; our findings provide evidence of the low risk of injury related to these events and posit participation in these types of competitions are relatively safe for most individuals. Moreover, and unlike what we hypothesised, athletes with more experience, and greater weekly participation in CrossFit training reported lower injury rates than those completing a fewer number of weekly sessions and total number of workouts.

Several aetiology models for risk injury exist, ${ }^{43} 44$ suggesting that sport injuries occur as an interaction between intrinsic (ie, age, muscular imbalances, etc) and extrinsic factors (ie, equipment, environment, etc); however, identifying this aetiology is difficult due to its multifactorial nature and methodological limitations from previous studies. ${ }^{43}{ }^{45}$ Recently, Windt and Gabbett ${ }^{45}$ postulated that training workloads can serve as a stimulus for injury by exposing athletes to unaccustomed workloads, yet it may also limit injury predisposition by inducing physiological adaptations specific to the sport; thereby, supporting the training-injury prevention paradox. ${ }^{46}$ Our findings, of lower injury rates among those with greater experience, although novel within the HIFT and CrossFit training literature, are in line with this proposed 'training-injury prevention paradox', and support the notion that injuries are not a result of higher training loads, instead they are the result of inappropriate and poor progression plans, which provide excessive and rapid increases in loads which an athlete may be physically unprepared to handle. ${ }^{4546}$ Considering the 'constantly varied' nature CrossFit training is based on, ${ }^{47}$ it is of utmost importance for individuals engaged in CrossFit training, as well as affiliate owners and coaches, to consider these data and develop programmes that are scalable according to an individual's athlete ability to promote safety, minimise injuries and maximise fitness gains among athletes.

As described by Feito et al in a recent review, ${ }^{6}$ the number of studies examining the incidence of injuries in this training modality have increased over the last decade. Since 2013, several studies have provided insight into the incidence and risks of musculoskeletal injuries associated with CrossFit training in the USA, ${ }^{145} 25448-50$ Brazil,${ }^{37}$ Italy, ${ }^{51}$ the Netherlands, ${ }^{52}$ Portuga ${ }^{53}$ and the UK. ${ }^{54}$ Collectively, these authors have reported injury rates of less than 3 injuries per 1000 hours, which is similar to other weight lifting sports, ${ }^{55}$ and considerably lower than injury rates
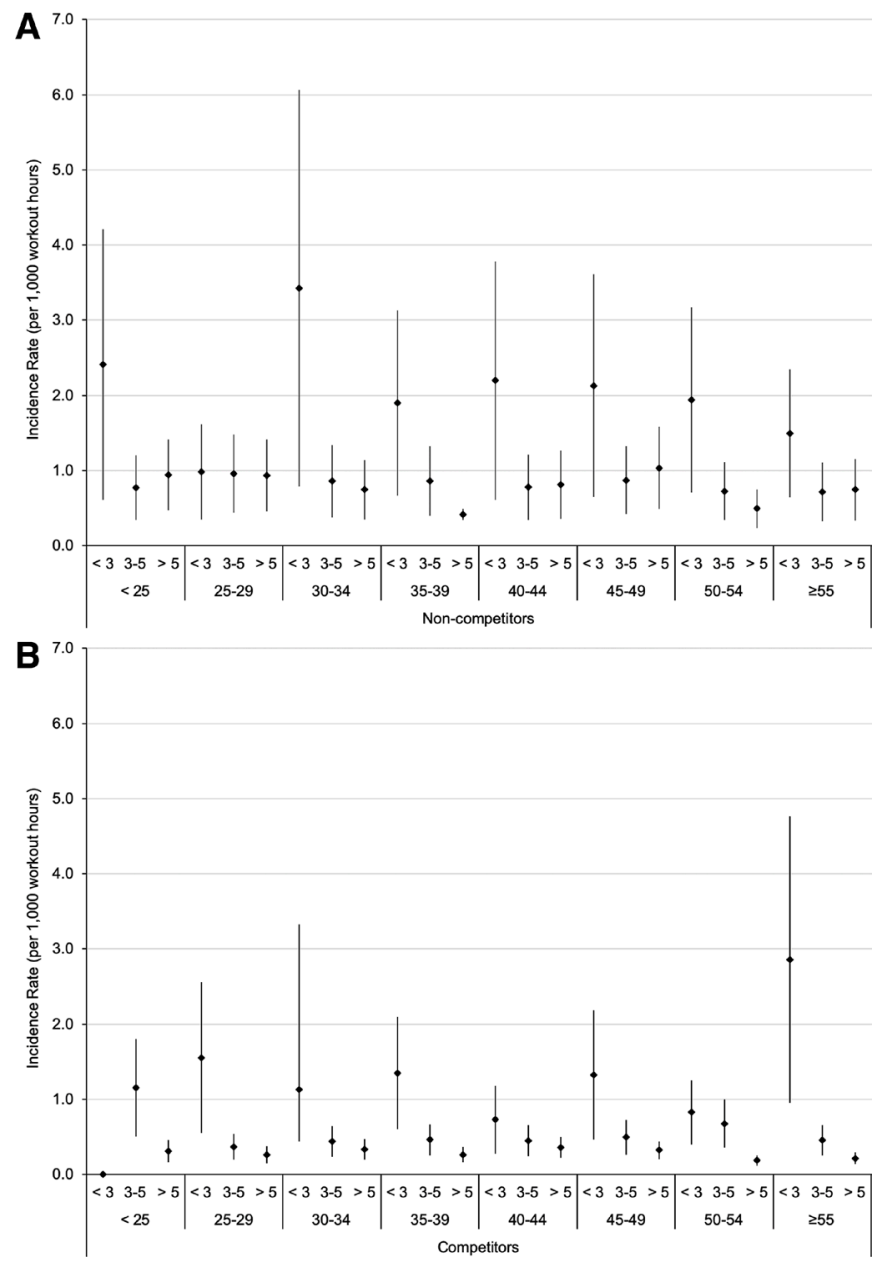

Figure 3 Incidence of injury among (A-upper panel) noncompetitors and $(\mathrm{B}$-lower panel) competitors by age-groups and frequency of training (days/week). Incidence rate mean with lower and upper bound assumptions for 50 and 52 weeks assumed for workouts per year, respectively. 
Table 2 Logistic regression model results for the odds of being injured in null (Model 1), reduced (Model 2) and fully (Model 3) adjusted settings for $3049(\mathrm{~N})$ participants

\begin{tabular}{|c|c|c|c|c|c|c|}
\hline & Model 1 & & Model 2 & & Model 3 & \\
\hline & OR & $95 \% \mathrm{Cl}$ & OR & $95 \% \mathrm{Cl}$ & OR & $95 \% \mathrm{Cl}$ \\
\hline (Intercept) & 2.27 & 2.11 to 2.46 & 4.88 & 2.75 to 8.68 & 5.74 & 3.07 to 10.77 \\
\hline Age (years) & & & 0.99 & 0.98 to 1.00 & 0.99 & 0.98 to 1.00 \\
\hline Male (vs female) & & & 0.91 & 0.78 to 1.07 & 0.91 & 0.77 to 1.07 \\
\hline BMI & & & 0.99 & 0.98 to 1.01 & 0.99 & 0.98 to 1.01 \\
\hline Trains at CrossFit affiliate (yes vs no) & & & 0.83 & 0.63 to 1.08 & 0.85 & 0.65 to 1.10 \\
\hline $\begin{array}{l}\text { Competition } \\
\text { (yes vs no) }\end{array}$ & & & 1.15 & 0.99 to 1.35 & 1.07 & 0.89 to 1.29 \\
\hline $\begin{array}{l}\text { Participation length } \\
\text { (reference: }>5 \text { years) }\end{array}$ & & & & & & \\
\hline$<6$ months & & & & & 1.82 & 1.15 to 2.92 \\
\hline$<12$ months & & & & & 0.79 & 0.56 to 1.13 \\
\hline $1-3$ years & & & & & 0.76 & 0.57 to 1.01 \\
\hline $3-5$ years & & & & & 0.76 & 0.57 to 1.01 \\
\hline AIC & 3754 & & 3746 & & 3727 & \\
\hline
\end{tabular}

Bold text indicates significance.

AIC, Akaike Information Criterion; BMI, body mass index.

related to more traditional training programmes. ${ }^{56}$ Our injury rates are in accordance with those reported previously in the literature and further emphasise the role of competition and weekly participation in injury risk. To our knowledge, this study is the first to provide insight into the risk of injury associated with CrossFit training competitions in a multi-year cross-sectional sample of athletes around the world.

Prior to 2018, the competition levels for CrossFit sanctioned events could be divided into three different categories, The Open, Regionals and The Games. In our study population, as is representative of the nature of these various groups, we had fewer participants in the Regional and The Games categories, with 123 (8\%) and $60(4 \%)$ competing in these two levels, respectively. As such, trying to draw conclusions from these distinct groups proved to be difficult due to the limited number of participants at each level. Nonetheless, to our knowledge, these findings are the first to provide insight into the incidence of injury among athletes competing in CrossFit sanctioned events-which speaks of the novelty in our study and ultimately in our findings. Recently, Montalvo et al suggested competitors in their sample reported more injuries compared with non-competitors ( $40 \%$ vs $19 \%$, respectively); however, no clear definitions of the type of competition were provided ${ }^{24}$; we presume competitors in their group were similar to the majority of those who reported participating in The Open in our sample, yet we cannot be certain this is the case. Additionally, even though competitors reported more injuries in that study, participation in competitions did not show to be a statistically significant factor in the logistic regression, suggesting that additional factors played a role in the injury prevalence of those competitors.

Minghelli and Vicente, ${ }^{53}$ reported on risk factors associated with injury among Portuguese CrossFit practitioners and concluded that those not competing had 2.64 higher probability of being injured (95\% CI: 1.37 to 5.09; $\mathrm{p}=0.004)$ compared with their competitor counterparts. More importantly, however, is the fact that those who trained less than three times a week had 3.24 higher probability of injury (95\% CI: 1.78 to $5.89 ; \mathrm{p} \leq 0.001$ ) than those who trained three or more times a week. These findings are in line with those reported here, as non-competitors and those engaging in less than 3 days of training had the highest risk of injury, suggesting that consistency with training, as well as adequate load progression models are important modulators of injury risk.

Although we believe our findings are novel and provide valuable evidence of the risk of injury among individuals engaged in CrossFit sanctioned competition events, we acknowledge the limitations of our survey tool. Specifically, the use of self-reported questions is subject to recall bias and could influence our findings, however, the use of this type of retrospective evaluation of injury is common practice in the literature and has presented to be valid depending on the level of recall detailed by the survey tool. ${ }^{57}$ In this regard, our mixed-methods design, where participants were able to provide both predetermined responses, and elaborate on other questions, could have minimised this recall bias and can provide valuable data in the topic. Moreover, we believe our sample size, which is the largest cross-sectional sample published to 
date, should be able to mitigate some limitations related to recall bias. Additionally, a lack of randomisation in our sample may have biased our findings, however, we believe providing a range in injury risk (lower and upper bounds, based on 50 or 52 weeks of participation in a given year) based on our participants training frequency provides a more accurate depiction of risk compared with other published studies. Similarly, and as suggested by Feito $e t a l,{ }^{25}$ if our study participants were mostly injured athletes, future studies should report lower incidence rates than those reported here. Lastly, our definition where a participant was asked if their injury resulted in consultation with a physician or healthcare provider may have influenced how a survey participant may have answered the question, as someone may have seen an alternative practitioner (eg, chiropractor, physical therapist, acupuncturist, etc) and not consider these medical practitioners as 'healthcare providers.'

In summary, we have provided novel evidence that participation in CrossFit sanctioned competition events does not carry significant injury risk, and that lack of experience with CrossFit training is a significant predictor of injury. Moreover, our findings are the first in the literature to suggest that training at an official CrossFit affiliate may result in less injuries compared with nonaffiliates; however, this requires further inquiry. Based on these findings, we would recommend individuals who have less than 12 months of experience to be cautious when participating in CrossFit sanctioned events and focus on completing workouts that are appropriate for their fitness and experience levels. Although the CrossFit Games have gained popularity around the world, it is imperative to note that athletes reaching The Games are at their peak physical performance and represent a very small percentage of those engaged in this training modality, similar to the 'Olympics' of other more traditional sports (ie, track and field, swimming, etc); thus, comparisons should be limited and training expectations should be considered so that performance is enhanced gradually and injury risk is minimised. Furthermore, we believe additional research and funding should be made available to accurately depict the risk of injury in this type of training modality considering the millions of individuals currently engaged in this type of training around the world.

\section{Twitter Yuri Feito @DrFeito}

Acknowledgements We appreciate the involvement of all the athletes around the world who participated in this survey over the years of collection; without their time and dedication these data would not be possible.

Contributors YF conceived and collected all data for the study. EB, K-AC and LT conducted data analysis. YF drafted the manuscript and EB, K-AC and LT edited the manuscript. All authors agree on the final version of the manuscript.

Funding This study was not funded by any external sources. This project was partially funded by a professional development grant from the Wellstar College of Health and Human Services at Kennesaw State University.

Competing interests None declared.

Patient consent for publication Not required.
Ethics approval The Kennesaw State University Institutional Review Board approved all aspects of this study (IRB \#13-167).

Provenance and peer review Not commissioned; externally peer reviewed.

Data availability statement Data are available upon reasonable request.

Open access This is an open access article distributed in accordance with the Creative Commons Attribution Non Commercial (CC BY-NC 4.0) license, which permits others to distribute, remix, adapt, build upon this work non-commercially, and license their derivative works on different terms, provided the original work is properly cited, appropriate credit is given, any changes made indicated, and the use is non-commercial. See: http://creativecommons.org/licenses/by-nc/4.0/.

ORCID iD

Yuri Feito http://orcid.org/0000-0001-6790-6294

\section{REFERENCES}

1 Pipes TV. Physiological responses of fire fighting recruits to high intensity training. J Occup Med 1977;19:129-32.

2 Lesmes GR, Fox EL, Stevens C, et al. Metabolic responses of females to high intensity interval training of different frequencies. Med Sci Sports 1978;10:229-32.

3 Thompson WR. Worldwide survey of fitness trends for 2018. ACSMs Health Fit J 2017;21:10-19.

4 Thompson WR. Worldwide survey of fitness trends for 2016: 10th anniversary edition. ACSM'S Health \& Fitness Journal 2015;19:9-18.

5 Feito Y, Heinrich KM, Butcher SJ, et al. High-Intensity functional training (HIFT): definition and research implications for improved fitness. Sports 2018;6. doi:10.3390/sports6030076. [Epub ahead of print: 07 Aug 2018].

6 Feito Y, Brown C, Olmos A. A content analysis of the high-intensity functional training literature: a look at the past and directions for the future. Human Movement 2019;20:1-15.

7 Claudino JG, Gabbett TJ, Bourgeois F, et al. CrossFit overview: systematic review and meta-analysis. Sports Med Open 2018;4:11.

8 Gianzina EA, Kassotaki OA. The benefits and risks of the highintensity CrossFit training. Sport Sci Health 2019;15:21-33.

9 Feito Y, Brown C, Box A, et al. An investigation into how motivational factors Differed among individuals engaging in CrossFit training. SAGE Open 2018;8:215824401880313.

10 Box AG, Feito Y, Brown C, et al. Individual differences influence exercise behavior: how personality, motivation, and behavioral regulation vary among exercise mode preferences. Heliyon 2019;5:e01459.

11 Friedman MV, Stensby JD, Hillen TJ, et al. Traumatic tear of the latissimus dorsi myotendinous junction: case report of a CrossFitRelated injury. Sports Health 2015;7:548-52.

12 Joondeph SA, Joondeph BC. Retinal detachment due to CrossFit training injury. Case Rep Ophthalmol Med 2013;2013:189837

13 Withrow K. Army physical (un)fitness: A system that promotes injury and poor nutrition, 2016. Available: https://www.armytimes.com/ 2016/08/19/army-physical-un-fitness-a-system-that-promotesinjury-and-poor-nutrition/ [Accessed 1 Aug 2017].

14 Chachula LA, Cameron KL, Svoboda SJ. Association of prior injury with the report of new injuries sustained during CrossFit training. Athl Train Sports Health Care 2016;8:28-34.

15 Cameron KL, Mountcastle SB, Nelson BJ, et al. History of shoulder instability and subsequent injury during four years of follow-up: a survival analysis. J Bone Joint Surg Am 2013;95:439-45.

16 Hägglund M, Waldén M, Ekstrand J. Previous injury as a risk factor for injury in elite football: a prospective study over two consecutive seasons. Br J Sports Med 2006;40:767-72.

17 Kucera KL, Marshall SW, Kirkendall DT, et al. Injury history as a risk factor for incident injury in youth soccer. Br J Sports Med 2005;39:462-62.

18 Poston WSC, Haddock CK, Heinrich KM, et al. Is High-Intensity Functional Training (HIFT)/CrossFit Safe for Military Fitness Training? Mil Med 2016;181:627-37.

19 Hopkins BS, Cloney MB, Kesavabhotla K, et al. Impact of CrossFitRelated spinal injuries. Clin J Sport Med 2017; Publish Ahead of Print.

20 Klimek C, Ashbeck C, Brook AJ, et al. Are injuries more common with crossfit training than other forms of exercise? J Sport Rehabil 2018;27:295-9.

21 Dominski FH, Siqueira TC, Serafim TT, et al. Injury profile in CrossFit practitioners: systematic review. Fisioterapia e Pesquisa 2018;25:229-39.

22 Domene PA, Clarke ND, Delextrat AA, et al. Injury surveillance of female adult Zumba ${ }^{\circledR}$ dancers. J Sports Med Phys Fitness 2017;57:1642-9. 
23 Raske A, Norlin R. Injury incidence and prevalence among elite weight and power lifters. Am J Sports Med 2002;30:248-56.

24 Montalvo AM, Shaefer $\mathrm{H}$, Rodriguez B, et al. Retrospective injury epidemiology and risk factors for injury in CrossFit. J Sports Sci Med 2017;16:53-9.

25 Feito Y, Burrows EK, Tabb LP. A 4-year analysis of the incidence of injuries among CrossFit-Trained participants. Orthop J Sports Med 2018;6:232596711880310.

26 CrossFit Inc. CrossFit Affiliate MAP, 2018. Available: http://map. crossfit.com/ [Accessed 20 Nov 2018].

27 Up MC. The 2018 CrossFit open: participation by the numbers: morning Chalk up, 2018. Available: https://morningchalkup.com/ 2018/04/02/the-2018-crossfit-open-participation-by-the-numbers/ [Accessed June 26 2019].

28 Shakhawala S. The CrossFit open 2019: out with the old, in with the new: wodprep.com, 2018. Available: https://wodprep.com/blog/ crossfit-open-2019-changes/ [Accessed August 10 2019].

29 Atkinson R, Flint J, Sampling S. Snowball Sampling. In: LewisBeck MS, Bryman A, Futing Liao T, eds. The SAGE encyclopedia of social science research methods. 1044. Thousand Oaks, CA: SAGE Publications Ltd, 2004.

30 Bonometti RJ, Tang J. A dynamic technique for conducting online survey-based research. Competitiveness Review: An International Business Journal 2006;16:97-105.

31 Reips U-D. Standards for Internet-based experimenting. Exp Psychol 2002;49:243-56.

32 Morse JM, Niehaus L. Mixed method designs: who needs it? mixed method design: principles and procedures. New York, NY: Routledge, 2016: 13-22.

33 Jensen MD, Ryan DH, Apovian CM, et al. 2013 AHAVACC/TOS guideline for the management of overweight and obesity in adults: a report of the American College of Cardiology/American heart association Task force on practice guidelines and the obesity Society. J Am Coll Cardiol 2014;63:2985-3023.

34 Weisenthal BM, Beck CA, Maloney MD, et al. Injury rate and patterns among CrossFit athletes. Orthop J Sports Med 2014;2:232596711453117.

35 Friis RH, Sellers TA. Measures of morbidity and mortality. epidemiology for public health practice. 5th edn. Burlington, MA: Jones \& Bartlett Learning, 2014: 107-55.

36 Merrill RM. Design strategies and statistical methods in descriptive epidemiology. Introduction to epidemiology. Sixth ed. Burlington, MA: Jones \& Bartlett Learning, 2013: 97.

37 Sprey JWC, Ferreira T, de Lima MV, et al. An epidemiological profile of CrossFit athletes in Brazil. Orthop J Sports Med 2016;4:232596711666370.

38 Chatterjee S, Price B. Regression analysis by example. 2nd Edn. New York, NY: Wiley-Interscience, 1991: 304.
39 Akaike H. Factor analysis and AIC. In: Parzen E, Tanabe K, Kitagawa G, eds. Selected papers of Hirotugu Akaike. New York, NY: Springer, 1987: 371-86.

40 Szumilas M. Explaining odds ratios. J Can Acad Child Adolesc Psychiatry 2010;19:227-9.

41 Henderson S. CrossFit's Explosive Affiliate Growth by the Numbers: Morning Chalk Up, 2018. Available: https://morningchalkup.com/ 2018/10/23/crossfits-explosive-affilaite-growth-by-the-numbers/ [Accessed 20 Nov 2018].

42 Up MC. So how many people participated in the 2019 CrossFit open? 2019. Available: https://morningchalkup.com/newsletters/ how-many-people-participated-in-the-2019-open/ [Accessed 26 Jun 2019].

43 Bahr R, Holme I. Risk factors for sports injuries--a methodological approach. Br J Sports Med 2003;37:384-92.

44 Mclntosh AS. Risk compensation, motivation, injuries, and biomechanics in competitive sport. Br J Sports Med 2005;39:2-3.

45 Windt J, Gabbett TJ. How do training and competition workloads relate to injury? the workload-injury aetiology model. Br J Sports Med 2017;51:428-35.

46 Gabbett TJ. The training-injury prevention paradox: should athletes be training smarter and harder? Br J Sports Med 2016;50:273-80.

47 Glassman G. What is CrossFit? The CrossFit Journal 2004:56:1-7.

48 Hak PT, Hodzovic E, Hickey B. The nature and prevalence of injury during CrossFit training. J Strength Cond Res 2013. doi:10.1519/ JSC.0000000000000318. [Epub ahead of print: 22 Nov 2013] (published Online First: 2013/11/28).

49 Giordano B, Weisenthal B. Prevalence and incidence rates are not the same: response. Orthop J Sports Med 2014;2:232596711454326.

50 Elkin JL, Kammerman JS, Kunselman AR, et al. Likelihood of injury and medical care between CrossFit and traditional Weightlifting participants. Orthop J Sports Med 2019;7:232596711984334.

51 Tafuri S, Notarnicola A, Monno A, et al. CrossFit athletes exhibit high symmetry of fundamental movement patterns. A cross-sectional study. Muscles Ligaments Tendons J 2016;6:157-60.

52 Mehrab M, de Vos R-J, Kraan GA, et al. Injury incidence and patterns among Dutch CrossFit athletes. Orthop J Sports Med 2017;5:232596711774526.

53 Minghelli B, Vicente P. Musculoskeletal injuries in Portuguese CrossFit practitioners. J Sports Med Phys Fitness 2019;59:1213-20.

54 Moran S, Booker H, Staines J, et al. Rates and risk factors of injury in CrossFitTM: a prospective cohort study. J Sports Med Phys Fitness 2017;57:1147-53.

55 Keogh JWL, Winwood PW. The epidemiology of injuries across the Weight-Training sports. Sports Med 2017;47:479-501.

56 Parkkari J, Kannus P, Natri A, et al. Active living and injury risk. Int J Sports Med 2004;25:209-16.

57 Gabbe BJ, Finch CF, Bennell KL, et al. How valid is a self reported 12 month sports injury history? Br J Sports Med 2003;37:545-7. 